\title{
A Cohort Study Evaluating the Association Between Concurrent Mental Disorders, Mortality, Morbidity, and Continuous Treatment Retention for Patients in Opioid Agonist Treatment (OAT) Across Ontario, Canada Using Administrative Health Data
}

Kristen A. Morin

Laurentian University

Joseph K. Eibl

Northern Ontario School of Medicine

Graham Gauthier

Northern Ontario School of Medicine

Brian Rush

Centre for Addiction and Mental Health

Christopher Mushquash

Lakehead University

Nancy E. Lightfoot

Laurentian University

David C. Marsh ( $\nabla$ dmarsh@nosm.ca)

Northern Ontario School of Medicine https://orcid.org/0000-0002-8769-1785

\section{Research}

Keywords: Opioid Use Disorder, Opioid Agonist Treatment, mental disorders

Posted Date: March 26th, 2020

DOI: https://doi.org/10.21203/rs.3.rs-19301/v1

License: (a) (i) This work is licensed under a Creative Commons Attribution 4.0 International License. Read Full License

Version of Record: A version of this preprint was published at Harm Reduction Journal on July 23rd, 2020. See the published version at https://doi.org/10.1186/s12954-020-00396-x. 


\section{Abstract}

Background: Due to the high prevalence of mental disorders among people with opioid use disorder, the objective of this study was to determine the association between concurrent mental disorders, mortality, morbidity and continuous treatment retention in opioid agonist treatment in Ontario, Canada.

Methods: We conducted a retrospective cohort study of patients enrolled in opioid agonist treatment between January 1, 2011, and December 31,2016. Patients were stratified into two groups: those diagnosed with concurrent mental disorders and opioid use disorder and those with opioid use disorder only, using data from the Ontario Health Insurance Plan Database, Ontario Drug Benefit Plan Database. The primary outcome studied was all-cause mortality using data from the Registered Persons Database. Emergency Department visits from the National Ambulatory Care Database, hospitalizations Discharge Abstract Database, and continuous retention in treatment, defined as one year of uninterrupted opioid agonist treatment using data from the Ontario Drug Benefit Plan Database, were measured as secondary outcomes. Encrypted patient identifiers were used to link across databases.

Results: We identified 55,924 individuals enrolled in opioid agonist treatment, $87 \%$ had a concurrent mental disorder diagnosis during this time period. We observed that having a mental disorder was predictive of allcause mortality (Odds Ratio (OR) 1.4; $95 \%$ Confidence Interval (CI) 1.2-1.5, frequent emergency department visits (OR 3.69; 95\% Cl 3.7-4.1) and hospitalizations (OR 2.6; 95\% $\mathrm{Cl} 2.5-2.7$ ). However it was not predictive for one-year treatment retention in OAT OR 1.0; $95 \% \mathrm{CI} 0.9-1.1)$.

Conclusion: Our findings highlight consequences of the high prevalence of mental disorders for individuals with opioid use disorder in Ontario, Canada.

\section{Introduction}

The expanding opioid crisis in Canada is a complex issue that is exacerbated by factors such as increased exposure to prescription opioids (1), prevalence of untreated mental illness (2), social isolation (3), a health system that does not work across silos, as well as largely unregulated advertising practices by drug companies $(4,5)$. Research examining substance use and psychiatric comorbidities have reported that approximately $50 \%$ of people with opioid use disorder (OUD) receiving treatment have a lifetime psychiatric diagnosis (6-10). In comparison to southern and urban communities, communities in northern Ontario (1115), Canada, including First Nations, rural, and remote communities, generally experience high poverty, have access to limited infrastructure and health resources, demonstrate high risk-taking behaviors, and have less control over their environment specific to weather and occupation. Such factors pose increased risk for mental disorders, substance use and suicide (16). Given the confluence of emergent factors and the ongoing nature of the relationships between these factors, it is likely that challenges with opioids will continue in Canada.

Opioid agonist treatment (OAT) is currently the intervention with the best evidence for long term treatment of OUD (17). However, retention in treatment continues to be a barrier for individuals with OUD. It is common for OAT patients to cycle through treatment and re-initiation of opioid consumption before they are stabilized in 
care, which can be dangerous because is changes opioid tolerance in patients leading to higher risk of mortality (19-24). Additionally, opioid-related deaths continue to be a critical issue in Ontario (25). For instance, approximately 4,000 Canadians died of opioid poisoning in 2017 (26). Moreover, there has been a surge in opioid-related hospitalizations and emergency department (ED) visits (27-29) increasing from an average of 9.42 per 100,000 population in 2003 to 19.55 per 100,000 population in 2015 (30).

According to the literature, mental disorders are prevalent among people with OUD $(3,7,8)$. Despite the high prevalence of mental disorders among individuals with OUD, current literature on how mental disorders impact the treatment of OUD is conflicting $(9,10)$. In this study, we characterize the relationship between mental disorders and outcomes in patients with OUD across Ontario. Our secondary objective was to examine regional variation in OAT and related issues $(28,34,35)$. We hypothesized that OAT patients with mental disorders had poorer outcomes compared to OAT patients with no mental disorders.

\section{Methods}

\section{Study Design}

A retrospective cohort study was conducted between January 1, 2011 and December 31, 2015. Every patient in the study was followed for one year. If patients started OAT at the end of 2015, they were followed until December 31, 2016. The first episode of OAT was used to identify patients, meaning that there was no previous history of OAT (including methadone or buprenorphine/naloxone) in the year prior to the first treatment episode. We chose to only include first-time OAT patients to eliminate bias associated with cases involving multiple treatment attempts. This study is reported in accordance with the Strengthening the Reporting of Observational Studies in Epidemiology (STROBE) guidelines (38)

\section{Study Population}

The study cohort was created with the Ontario Drug Benefit Plan (ODB) database using drug identification numbers (DIN) (see Appendix A); and with the Ontario Health Insurance Plan (OHIP) database using physician billing codes (see Appendix B). In previous published ICES studies $(13,23,27)$, the ODB database was used as the primary source to identify OAT patients. However, in Ontario, residents are only eligible for ODB public drug coverage if they are aged 65 years or older, reside in a long-term care facility, are disabled, are receiving social benefits for income support, or have high prescription drug costs relative to their net household income. Since 2011, new billing codes have helped to clearly identify OAT services (28) in administrative databases. OHIP coverage is available to all permanent residents of Ontario. Therefore, in order to avoid excluding a subset of the population and risking selection bias, we used both ODB and OHIP databases to identify the primary patient cohort. 
The study included patients over $15 y$ ears of age ( $n=2,535$ patients). Patients with over $20 \%$ of their methadone dose in tablet formulation over a one-year period were excluded due to the likelihood that methadone was being administered for chronic pain ( $n=5,560$ patients). Additionally, patients who were not eligible for OHIP ( $n=437$ patients), non-Ontario residents ( $n=427$ patients), as well as those with missing age, gender and postal codes $(n=0$ patients) were excluded from the study. See Figure 1 .

\section{Data Sources}

Individual-level data collected from Ontario publicly funded health services from ICES was accessed for the analysis. ICES is an independent research institute that collects and analyzes health care data for research. Patient information was linked anonymously across databases using encrypted 10-digit health card numbers. The linking protocol is used routinely for health system research in Ontario (41-43).

All diagnostic information from physician visits were determined using billing data from OHIP. ED visits were identified using the National Ambulatory Care Reporting System (NACRS). Hospital admissions were identified using the Discharge Abstract Database (DAD). We obtained patients' location of residence and demographic information including all-cause mortality from the Ontario Registered Persons Database (RPDB) which contains unique data for each resident who has ever received insured health.

\section{Patients with a diagnosis of one or more mental disorders}

Diagnosis of one or more mental disorders was assumed for all patients who had at least one of the OHIP diagnosis listed in Appendix D. In the database used to identify diagnoses of mental disorders, substance dependence falls under one category, under one code (304). All patients in the cohort had that code based on their opioid dependence. Therefore, there was no way to detect those who also have dependence on cocaine, benzodiazepines or other substances. For this reason, we excluded substance use disorders from our mental disorder diagnosis definition,

Patients were assigned to only one of the following groups: those diagnosed with a mental disorder other than OUD and those not diagnosed with a mental disorder other than OUD. Mental disorders can be chronic, re-occurring conditions therefore, we chose to define a wide time parameter to identify those with mental disorders from one-year prior to the time of their first OAT event to one-year after the date of their last OAT event (or the study end date) in order to accurately capture the condition. 


\section{Outcomes}

The all-cause mortality variable was requested from ICES as a dichotomized variable. All-cause mortality included opioid-related and non-opioid related mortalities. At the time of the study, mortality specific data were not available for the entirety of our study period. Data from the RPDB database was used to calculate the number of days to death date from the study index date for each patient in the cohort to create the variable. If the patient had a mortality event anytime between their index date and the end of the study period (December 31, 2016), we assigned a code of 1 (all-cause mortality) or 0 (no all-cause mortality).

The DAD database was used to identify hospitalization. Hospitalizations were captured in three groups: opioid-related, mental health-related, and for reasons other than mental health or opioids using the primary diagnosis code that accompanied the hospitalization event in the DAD database. Hospitalizations were dichotomized and counted if a hospitalization discharge record appeared after a patient's index date in a publicly funded Ontario hospital.

A subgroup analysis of one-year treatment retention was conducted using the ODB database $(n=25,800)$. One-year retention in OAT was assessed on the basis of doses dispensed (from ODB database) within 30 days of the previous dispensed dose. Thirty days was chosen based on the use of this interval in previously published research $(19,56,57)$. The database used for medication dispensing in this study might not capture doses administered in hospital or provincial correctional settings. However, in Ontario, patients will typically continue to receive methadone or buprenorphine in these settings. Since most hospital admissions or provincial incarcerations are less than 30 days, this approach allowed us to conduct the analysis without misinterpreting such events as treatment interruption.

\section{Baseline Covariates}

The covariates available for the study included age, sex, location of residence, income quintile, human immunodeficiency virus infection (HIV), deep tissue infection including endocarditis (OHIP diagnostic code 429), osteomyelitis (OHIP diagnostic code 730) and septic arthritis (OHIP diagnostic code 711).

\section{Statistical Analysis}


Descriptive statistics were calculated for exposure groups. Chi-square statistic was used to compare categorical variables and Wilcoxon rank-sum test to compare continuous variable between exposure groups. Logistic regression models were applied to test the association between mental disorders and all-cause mortality, ED visits, hospitalizations and, on the subgroup to study one-year treatment retention adjusting for patient covariates. Odds ratios $(\mathrm{OR})$ and $95 \%$ confidence intervals $(\mathrm{Cl})$ were calculated for each OR. Results were considered statistically significant where $p<0.05$. All statistical analyses was conducted from the secure server using SAS Version 9.4 (58). Data was reviewed by ICES to insure privacy standards were met.

\section{Results}

A total of 55,924 patients who were enrolled in OAT between 2011 and 2015 were identified. Of those, 48,679 $(87.0 \%)$ had one or more diagnoses of concurrent mental disorder. There were 534 records with missing information on income quintile and 3 records with missing information on location of residence. Missing income records were re-assigned to the lowest income group and those with missing information on location of residence were deleted.

\section{Prevalence of Mental Disorders}

Anxiety disorders, including obsessive compulsive disorder, and other anxiety-related disorders (60\%), and mood disorders including bipolar and other depressive-related disorders (20\%) were among the most prevalent in the cohort. Results are presented in Figure 2.

\section{Patient Characteristics}

Males represented a lower proportion of individuals in the mental disorders group (63.0\%) compared to the group with no mental health disorder $(77.0 \%,(p<0.001)$. The proportion of individuals aged 15 to 34 in the mental disorders and no mental disorders groups was $51.1 \%$ and $60.4 \%$ respectively. The proportion of individuals with mental disorders was $87.9 \%$ in southern urban regions, $85.5 \%$, in southern rural, $85.6 \%$ in northern urban and $79.0 \%$ in northern rural regions $(p<0.001)$. There were significant differences between the two groups with regards to the proportion of patients with HIV (concurrent group $=0.8 \%$ and OUD only group $=0.3 \%, \mathrm{p}<0.001$ ) ) and deep tissue infections (concurrent group $=3.3 \%$, and OUD only group $=1.3 \%, \mathrm{p}<$ $0.001)$ ). Retention in buprenorphine treatment was significantly different between groups (mean days engaged in buprenorphine treatment was 55.0, standard deviation (SD) $=167.8$, and $34.8, S D=121.8$ ). Results are outlined in Table 1. 


\section{Outcomes}

Having a diagnosis of one or more mental disorders was associated with all-cause mortality (adjusted OR $(\mathrm{aOR})=1.4 ; 95 \%$ confidence interval $(\mathrm{Cl}) 1.2$ to 1.5$)$. Additionally, having a diagnosis of one or more mental disorders was also associated with frequent $\mathrm{ED}$ visits ( $\mathrm{aOR}=3.9 ; 95 \% \mathrm{Cl} 3.7$ to 4.1$)$ and hospitalizations $(\mathrm{aOR}=2.6 ; 95 \% \mathrm{Cl} 2.5$ to 2.7$)$. However, having one or more mental disorders was not associated with oneyear treatment retention in OAT $(\mathrm{aOR}=1.0 ; 95 \% \mathrm{Cl} 0.9$ to 1.1$)$. Results are outlined in Table 3-5.

\section{Regional Differences}

The highest proportion of patients who died was in southern urban areas $(n=2,039,5.38 \%)$ and the lowest in northern rural areas $(n=68,3.04 \%, p<0.001)$, whereas the highest proportion of patients with frequent ED visits was in northern rural areas $(n=1,880,83.93 \%)$ and the lowest in southern urban areas $(n=29,137$, $55.81 \%, \mathrm{p}<0.001)$. Similarly, the highest proportion of patients with hospitalizations was in northern rural areas $(n=1,917,85.58 \%)$ and the lowest were in southern urban areas $(n=36,032,71.72 \%, p<0.001)$. The highest proportion of patients retained for one year was in southern rural areas $(n=347,37.1 \%)$, followed by northern urban $(n=456,36.5 \%)$, southern urban $(n=2,630,35.1 \%)$ and lastly northern rural $(n=173,29.1 \%$, $\mathrm{p}<0.001)$. Results are described in Figure 3.

\section{Discussion}

The study objective was to characterize the relationship between having a diagnosis of one or more mental disorders and a variety of health-related outcomes among patients with OUD across Ontario. In this cohort, having one or more mental disorders and OUD was associated with an increased likelihood of all-cause mortality and acute health care use. It was also noted that a higher proportion of patients were using acute health services more frequently in northern rural regions compared to southern urban areas.

The results of this study align with the current studies which demonstrate a high prevalence of mental disorders in the OUD population $(7,33,59)$. However, in this study, $87 \%$ of the population had a mental disorder whereas the prevalence in the literature is approximately $50 \%(7,33,59)$. The high prevalence identified in our cohort may be due to the fact that we examined a broad range of disorders and that our time parameter including study time and follow-up was much longer than in other studies $(6,7)$. The study time period was also much more recent and may be more representative of the current issues in Canada relating to patients in OAT. Similar to other studies, we also found that mental disorders in the OAT population are associated with a more complex clinical course $(7,60-62)$. 
In our study, having one or more mental disorders was associated with all-cause mortality when compared to the group that was not diagnosed with mental disorders. This finding is congruent with a study by Saunders et al. suggesting that individuals with OUD who have psychiatric symptoms have higher rates of overdose, decreased quality of life and higher rates of continual substance use (66). It is important to note that the results indicate that individuals with mental health comorbidities are a complex group of patients; however, results should be interpreted with caution. It is possible that either the use of opioids is especially harmful for individuals with mental disorders or that the use of opioids might aggravate a pre-existing condition (67). For many, OUD is a lifelong illness associated with serious chronic health and social outcomes (48).

Dichotomizing all-cause mortality allowed us to evaluate death associated with chronic mental disorders and OUD, and not necessarily as concurrent disorders leading to an event. We believe that future studies should be conducted to evaluate deaths as a function of length of time in treatment to further explore this issue.

Despite the differences in mortality and morbidity between exposure groups, in this study, having one or more mental disorders was not associated with one-year retention in OAT. Some authors report that mental disorders increase retention (60) and some have reported no effect (33). We believe that research exploring concepts of resilience and motivation would be critical to further explain this relationship. It is important to note that the cohort had lower one-year retention rates (approximately 40\%) than cohorts represented in other studies (approximately 50\%) $(69,70)$. The lower average retention rates may be attributed to the fact that we included buprenorphine/naloxone medication in our analysis. In this study, patients on buprenorphine/naloxone had much lower retention rates (mean of approximately 40 days retained on buprenorphine vs. mean of 350 days retained on methadone) see Table 1. Lower retention for patients receiving buprenorphine are also highlighted in other studies $(71,72)$.

We identified a trend where patients in the cohort residing in southern urban regions of Ontario had the highest prevalence of all-cause mortality. A cohort study by Gomes et al., on geographic variation in opioid prescribing and opioid-related mortality in Ontario (34) found that communities with some of the highest rates of opioid-related death were in northern Ontario. One possible factor accounting for higher mortality rates in southern urban regions is the unprecedented increased fentanyl-related deaths in recent years which started in urban centers and is now making its way into smaller communities (73). Another possible explanation is that barriers to access OAT are higher in northern Ontario perhaps resulting in a larger number of deaths among individuals who were never enrolled in OAT (and thus not included in this study).

Although the results show lower prevalence of all-cause mortality in northern regions, there was a significantly higher proportion of morbidity measured by ED visits and hospitalizations in northern rural Ontario. The high acute care use may be attributed to the well-known limited availability of specialist addiction medicine and psychiatric services in northern rural regions of Ontario $(35,74)$. Lastly, with regards 
to geographical variation, our results demonstrated that the proportion of patients retained for one-year of OAT treatment was highest for those living in southern rural areas. This is counter to the findings published by Eibl et al. (70) which demonstrated that patients living in northern rural areas were more likely to be retained for one year. Importantly, the time frame for our study is more recent than the earlier study by Eibl et al. and currently there is a wider availability of buprenorphine/naloxone. However, further study is needed on region-specific retention for individuals with concurrent mental disorders and OUD including analysis of changes over time and the impact of changing rates of methadone and buprenorphine/naloxone prescribing.

One of the potential issues inherent to any study of this type is that health administrative data were not collected for the purposes of doing research which may have led to misclassification of disease prevalence and clinical outcomes. For instance, we were not able to evaluate patients who may have a mental disorder or OUD who have not yet sought out services (75). We also only examined OHIP billed mental health services, which by default excluded the use of Ministry of Health-funded community mental health and addiction services, and federally funded health services, such as mental health and addiction services provided in First Nation communities, as well as any other mental health and addiction services funded by provincial ministries other than the Ministry of Health. Moreover, since there is a well-known lack of physicians available to diagnose and treat patients in rural areas, we may have underestimated the prevalence of mental disorders and other diagnoses.

With relation to mental diagnoses, further stratification of diagnosis type would have been of interest, but was not possible as the numbers became too small to publish for the outcomes of interest. It is important to highlight the potential underestimation of the prevalence of post-traumatic stress disorder (PTSD) since it is known to be often misdiagnosed as another anxiety, depression or other related disorders (76-79). Details such as years of drug use, the amount or type of opioid used, the history of mental health services prior to one year before the first episode of OAT and the number of times patients were in and out of OAT after their first episode of OAT in this study remains unknown. Since this study is observational in nature, causality cannot be inferred. Additionally, there is a potential for associations to be significant by chance due to the large sample size.

There are also limitations associated with the way we measured the outcomes for this study. Some authors have stated that creating categories from continuous data can lead to loss of information (80). More specifically, there are limitations to using all-cause mortality as a dichotomized variable without censoring for time. For instance, for those patients where all-cause mortality occurred during the first year of OAT, the likelihood of one-year retention is reduced. However, the function of time is a modest bias since we observed an increase in ED visits and hospitalizations in the groups with the highest mortality. Additionally, the definition of frequent ED visits has not been validated. Previous studies have used definitions ranging from 2 to $20 \mathrm{ED}$ visits per year to define frequent $\operatorname{ED}$ use $(81,82)$. In an effort to evaluate the sensitivity of the 
definition used in this thesis, we re-ran the data with different cut-offs (with a median of 13 visits and 14 visits. Our sensitivity analysis indicated that we chose a conservative cut-off since taking progressively higher cut-offs led to progressively higher odds ratio. See Appendix E for sensitivity analysis results. The results of this study which were found to be statistically significant must be interpreted critically within the context of the population of interest to determine whether the results have a clinical or health system impact.

\section{Conclusion}

The outcomes of this study have important implications for those involved in health care planning and policy development because our data suggest that the prevalence of mental disorders in the OAT population is alarmingly high and that mental disorders are associated with serious consequences. Currently, the regulations and model of care for OAT in Ontario promotes access to services, but does not incentivize efforts towards coordination with other parts of the health care system including other addiction or mental health services. Results may be generalizable in regions where OAT programs and health care regulations are similar to those in Ontario. Further study is needed to determine the effectiveness of concurrent delivery of mental health, other substance use and OAT services.

\section{Abbreviations}

OUD Opioid Use Disorder

OAT Opioid Agonist Treatment

ICES Formally known as the Institute for Clinical Evaluative Sciences

ODB Ontario Drug Benefit Plan

SAS Statistical Analytics Software

OHIP Ontario Health Insurance Plan

ED Emergency Department

ClHI Canadian Institute for Health Information

NACRS National Ambulatory Care Reporting System

DAD Discharge Abstract Database

RPDB Registered Persons Database

LHIN Local Health Integration Network

OR Odds Ratio 

aOR
Adjusted Odds Ratio
Cl Confidence Interval
ICD International Classification of Disease
PTSD Post-Traumatic Stress Disorder
HIV Human Immunodeficiency Virus

ODPRN Ontario Drug Policy Research Network

\section{References}

1. Canadian Institute for Health Information: Pan-Canadian Trends in the Prescribing of Opioids, 2012 to 2016 Ottawa ON 2017 [Available from: https://www.cihi.ca/sites/default/files/document/pan-canadiantrends-opioid-prescribing-2017-en-web.pdf].

2. Van Ameringen M, Mancini C, Patterson B, Boyle MH. Post-traumatic stress disorder in Canada. CNS Neurosci Ther. 2008;14(3):171-81.

3. WHO. World Health Organization. Principles of Drug Dependence Treatment Geneva, Switzerland: World Health Organization; 2008 [Available from: http://www.who.int/substance_abuse/publications/principles_drug_dependence_treatment.pdf?ua=1].

4. Public Health Agency of Canada. Notice of Intent to Restrict the Marketing and Advertising of Opioids Ottawa Ontario 2018 [Available from: https://www.canada.ca/en/health-canada/services/drugs-healthproducts/drug-products/announcements/restrict-advertising-opioids.html].

5. Webster P. Oversight of opioid advertising in Canada remains lax despite new federal guidance. CMAJ. 2018;190(23):E730-E1.

6. Astals M, Domingo-Salvany A, Buenaventura CC, Tato J, Vazquez JM, Martin-Santos R, et al. Impact of substance dependence and dual diagnosis on the quality of life of heroin users seeking treatment. Subst Use Misuse. 2008;43(5):612-32.

7. Bogdanowicz KM, Stewart R, Broadbent M, Hatch SL, Hotopf M, Strang J, et al. Double trouble: Psychiatric comorbidity and opioid addiction-all-cause and cause-specific mortality. Drug Alcohol Depend. 2015;148:85-92.

8. Griffin MLD, R.D.; Potter, J.S. Baseline characteristics andtreatment outcomes in prescription opioid dependent patients with andwithout co-occurring psychiatric disorder. Am J Drug Alcohol Abuse. 2015;40:157-62.

9. Saunders EC, McGovern MP, Lambert-Harris C, Meier A, McLeman B, Xie H. The impact of addiction medications on treatment outcomes for persons with co-occurring PTSD and opioid use disorders. Am J Addict. 2015;24(8):722-31.

10. Brooner RK, King VL, Kidorf M, Schmidt CW, Jr., Bigelow GE. Psychiatric and substance use comorbidity among treatment-seeking opioid abusers. Arch Gen Psychiatry. 1997;54(1):71-80. 
11. Brannen CD, K.; Hardy, C.; Mushquash, C. Rural Mental Health Services in Canda: A Model for Research and Practice. In: Kulig JW, A., editor. Health in Rural Canada. Vancouver, BC, Canada: UBC Press; 2012. p. 239-55.

12. Canadian Institute for Health Information. Canadian Population Health Initiative. How Healthy Are Rural Canadians? An assessment of their health status and health determinants. Canadian Institute for Health Information; 2006.

13. Ward M. Short Report\#5: Mental Health in Northern Ontario. Northern Health Information Partnership; 2005.

14. Minore B, M. Boone, M.E. Hill, A. Lyubechansky, R. Kuzik, and C. Macdonald. . Towards Using Family Health Teams to Care for Chronic Mental Health Clients in Northern Ontario: Barriers, Opportunities and Training Needs. Centre for rural and Northern Health Research, Lakehead University; 2005.

15. J. H. Rural Health and the Health of Rural Communities. . 1998.

16. World Health Organization: Prevention of Mental Disroders. Summary Report Geneva Switzerland: WHO; [Available from:

http://www.who.int/mental_health/evidence/en/prevention_of_mental_disorders_sr.pdf].

17. Mattick RP, Breen C, Kimber J, Davoli M. Methadone maintenance therapy versus no opioid replacement therapy for opioid dependence. Cochrane Database Syst Rev. 2009(3):CD002209.

18. Ontario Drug Policy Research Network. Ontario Prescription Opioid Tool. . Toronto, ON.

19. Nosyk B, Marsh DC, Sun H, Schechter MT, Anis AH. Trends in methadone maintenance treatment participation, retention, and compliance to dosing guidelines in British Columbia, Canada: 1996-2006. J Subst Abuse Treat. 2010;39(1):22-31.

20. Bell J, Burrell T, Indig D, Gilmour S. Cycling in and out of treatment; participation in methadone treatment in NSW, 1990-2002. Drug Alcohol Depend. 2006;81(1):55-61.

21. Galai N, Safaeian M, Vlahov D, Bolotin A, Celentano DD, Study A. Longitudinal patterns of drug injection behavior in the ALIVE Study cohort,1988-2000: description and determinants. Am J Epidemiol. 2003;158(7):695-704.

22. Dobler-Mikola A, Hattenschwiler J, Meili D, Beck T, Boni E, Modestin J. Patterns of heroin, cocaine, and alcohol abuse during long-term methadone maintenance treatment. J Subst Abuse Treat. 2005;29(4):259-65.

23. Bovasso G, Cacciola J. The long-term outcomes of drug use by methadone maintenance patients. J Behav Health Serv Res. 2003;30(3):290-303.

24. Termorshuizen F, Krol A, Prins M, Geskus R, van den Brink W, van Ameijden EJ. Prediction of relapse to frequent heroin use and the role of methadone prescription: an analysis of the Amsterdam Cohort Study among drug users. Drug Alcohol Depend. 2005;79(2):231-40.

25. Hedegaard H, Warner, M. Miniño, A. M. Drug Overdose Deaths in the United States, 1999-2016 NCHS Data Brief No. 2942017 [Available from: https://www.cdc.gov/nchs/products/databriefs/db294.htm].

26. Public Health Agency of Canada. Statement from the Co-Chairs of the Special Advisory Committee on the Epidemic of Opioid Overdoses on Updates to Opioid-Related Mortality Data. Ottawa, ON2018 
[Available from: https://www.canada.ca/en/public-health/news/2018/03/statement-from-the-co-chairsof-thespecial-advisory-committee-on-the-epidemic-of-opioid-o.html].

27. Gomes T GS, Martins D. Latest Trends in Opioid-Related Deaths in Ontario: 1991 to 2015 Toronto: Ontario Drug Policy Research Network; 2017 [Available from: http://odprn.ca/wpcontent/uploads/2017/04/ODPRN-Report_Latest-trends-in-opioid-related-deaths.pdf].

28. Martins D GS, Tadrous M, Paterson M, Bandola D, Singh S, Juurlink D, Mamdani M, Gomes T. Opioid Use and Related Adverse Events in Ontario. Ontario Drug Policy Research Network Toronto Ontario: ODPRN; 2016 [Available from: http://odprn.ca/wp-content/uploads/2016/11/ODPRN-Opioid-Use-and-RelatedAdverse-Events-Nov-2016.pdf].

29. Canadian Institute for Health Information, Canadian Centre on Substance Abuse. Hospitalizations and Emergency Department Visits Due to Opioid Poisoning in Canada. Ottawa ON: ClHl; 2016 [Available from: https://secure.cihi.ca/free_products/Opioid\%20Poisoning\%20Report\%20\%20EN.pdf].

30. Kingston Frontenac and Addington Public Health Unit Kingston, Ontario, Canada: KFL\&A Public Health Informatics [Available from: https://public.tableau.com/profile/kflaphi\#!/vizhome/OntarioOpioidSurveillanceMonitor/ACESEDVisits].

31. Amato L, Minozzi S, Davoli M, Vecchi S. Psychosocial combined with agonist maintenance treatments versus agonist maintenance treatments alone for treatment of opioid dependence. Cochrane Database Syst Rev. 2011(10):CD004147.

32. Dugosh K, Abraham A, Seymour B, McLoyd K, Chalk M, Festinger D. A Systematic Review on the Use of Psychosocial Interventions in Conjunction With Medications for the Treatment of Opioid Addiction. $J$ Addict Med. 2016;10(2):91-101.

33. Astals M, Diaz L, Domingo-Salvany A, Martin-Santos R, Bulbena A, Torrens M. Impact of co-occurring psychiatric disorders on retention in a methadone maintenance program: an 18-month follow-up study. Int J Environ Res Public Health. 2009;6(11):2822-32.

34. Gomes T, Juurlink D, Moineddin R, Gozdyra P, Dhalla I, Paterson M, et al. Geographical variation in opioid prescribing and opioid-related mortality in Ontario. Healthcare Quarterly. 2011;14(1):22-4.

35. Kiepek N, Groom B, Toppozini D, Kakekagumick K, Muileboom J, Kelly L. Evaluation of an inpatient medical withdrawal program in rural Ontario: a 1-year prospective study. Can J Rural Med. 2015;20(3):92-7.

36. Volkow ND. America's Addiction to Opioids: Heroin and Prescription Drug Abuse [Available from: https://www.nih.gov/sites/default/files/institutes/olpa/20140514-senate-testimony-volkow.pdf].

37. Nosyk B, MacNab YC, Sun H, Fischer B, Marsh DC, Schechter MT, et al. Proportional hazards frailty models for recurrent methadone maintenance treatment. Am J Epidemiol. 2009;170(6):783-92.

38. von Elm E, Altman DG, Egger M, Pocock SJ, Gotzsche PC, Vandenbroucke JP, et al. [The Strengthening the Reporting of Observational Studies in Epidemiology (STROBE) statement: guidelines for reporting observational studies]. Rev Esp Salud Publica. 2008;82(3):251-9.

39. Levy AR, O'Brien BJ, Sellors C, Grootendorst P, Willison D. Coding accuracy of administrative drug claims in the Ontario Drug Benefit database. Can J Clin Pharmacol. 2003;10(2):67-71. 
40. Hall S, Schulze K, Groome P, Mackillop W, Holowaty E. Using cancer registry data for survival studies: the example of the Ontario Cancer Registry. J Clin Epidemiol. 2006;59(1):67-76.

41. Mamdani M, Rochon P, Juurlink DN, Anderson GM, Kopp A, Naglie G, et al. Effect of selective cyclooxygenase 2 inhibitors and naproxen on short-term risk of acute myocardial infarction in the elderly. Arch Intern Med. 2003;163(4):481-6.

42. Juurlink DN. Proton pump inhibitors and clopidogrel: putting the interaction in perspective. Circulation. 2009;120(23):2310-2.

43. Juurlink DN, Gomes T, Lipscombe LL, Austin PC, Hux JE, Mamdani MM. Adverse cardiovascular events during treatment with pioglitazone and rosiglitazone: population based cohort study. BMJ. 2009;339:b2942.

44. Canadian Institute for Health Information. The Canadian Enchancement of ICD-0 (International Statistical Classification of Diseases and Health Related Problems), Ninth Revision 2015 [Available from: https://www.cdc.gov/nchs/icd/icd9cm.htm].

45. Durbin J LE, Rush B. A Study of Hospital Emergency Service Use, Crisis Service Delivery and Police Response After Mental Health System Enhancements. 2010.

46. Genell Andren K, Rosenqvist U. Heavy users of an emergency department-a two year follow-up study. Soc Sci Med. 1987;25(7):825-31.

47. Althaus F, Paroz S, Hugli O, Ghali WA, Daeppen JB, Peytremann-Bridevaux I, et al. Effectiveness of interventions targeting frequent users of emergency departments: a systematic review. Ann Emerg Med. 2011;58(1):41-52 e42.

48. Hser YI, Hoffman V, Grella CE, Anglin MD. A 33-year follow-up of narcotics addicts. Arch Gen Psychiatry. 2001;58(5):503-8.

49. Health Quality Ontario. Underpressure, emergency department performance in Ontario Toronto, Ontario, Canada 2017 [Available from: http://underpressure.hqontario.ca/chapter-1/].

50. Canadian Institute of Health Information. Sources of Potentially Avoidable Emergency Department Visits Toronto, Ontario 2014 [Page 11]. Available from:

https://secure.cihi.ca/free_products/ED_Report_ForWeb_EN_Final.pdf].

51. Under Pressure Emergency department performance in Ontario Toronto, Ontario: Health Quality Ontario; 2016 [Available from: https://www.hqontario.ca/portals/0/Documents/system-performance/underpressure-report-en.pdf].

52. Enhancing the Continuum of Care: Report of the Avoidable Hospitalization Advisory Panel Toronto, Ontario: Ministry of Health and Long-Term Care; 2011 [Available from: http://www.health.gov.on.ca/en/common/ministry/publications/reports/baker_2011/baker_2011.pdf].

53. Byrne M, Murphy AW, Plunkett PK, McGee HM, Murray A, Bury G. Frequent attenders to an emergency department: a study of primary health care use, medical profile, and psychosocial characteristics. Ann Emerg Med. 2003;41(3):309-18.

54. Ruger JP, Richter CJ, Spitznagel EL, Lewis LM. Analysis of costs, length of stay, and utilization of emergency department services by frequent users: implications for health policy. Acad Emerg Med. 2004;11(12):1311-7. 
55. Hunt KA, Weber EJ, Showstack JA, Colby DC, Callaham ML. Characteristics of frequent users of emergency departments. Ann Emerg Med. 2006;48(1):1-8.

56. Peles E, Linzy S, Kreek M, Adelson M. One-year and cumulative retention as predictors of success in methadone maintenance treatment: a comparison of two clinics in the United States and Israel. J Addict Dis. 2008;27(4):11-25.

57. Franklyn AM, Eibl JK, Gauthier G, Pellegrini D, Lightfoot NK, Marsh DC. The impact of benzodiazepine use in patients enrolled in opioid agonist therapy in Northern and rural Ontario. Harm Reduct J. 2017;14(1):6.

58. SAS version 9.4 Cary, North Carolina [Available from: https://www.sas.com/en_us/software/sas9.html].

59. Andrews G, Henderson S, Hall W. Prevalence, comorbidity, disability and service utilisation. Overview of the Australian National Mental Health Survey. Br J Psychiatry. 2001;178:145-53.

60. Gelkopf M, Weizman T, Melamed Y, Adelson M, Bleich A. Does psychiatric comorbidity affect drug abuse treatment outcome? A prospective assessment of drug abuse, treatment tenure and infectious diseases in an Israeli methadone maintenance clinic. Isr J Psychiatry Relat Sci. 2006;43(2):126-36.

61. McLellan ATL, L.; Woody, G. E.; O'Brien, C. P.; Druley, K. A. Predicting response to alcohol and drug abuse treatments. Role of psychiatric severity. Arch Gen Psychiatry. 1983;40(6):620-5.

62. Verthein U, Degkwitz P, Haasen C, Krausz M. Significance of comorbidity for the long-term course of opiate dependence. Eur Addict Res. 2005;11(1):15-21.

63. Gravel R, Beland Y. The Canadian Community Health Survey: mental health and well-being. Can J Psychiatry. 2005;50(10):573-9.

64. Parrish KH, Atherton OE, Quintana A, Conger RD, Robins RW. Reciprocal relations between internalizing symptoms and frequency of alcohol use: Findings from a longitudinal study of Mexican-origin youth. Psychol Addict Behav. 2016;30(2):203-8.

65. Mushquash AR, Stewart SH, Sherry SB, Sherry DL, Mushquash CJ, Mackinnon AL. Depressive symptoms are a vulnerability factor for heavy episodic drinking: a short-term, four-wave longitudinal study of undergraduate women. Addict Behav. 2013;38(5):2180-6.

66. Saunders EC, McGovern MP, Lambert-Harris C, Meier A, McLeman B, Xie H. The impact of addiction medications on treatment outcomes for persons with co-occurring PTSD and opioid use disorders. Am J Addict. 2015.

67. Rounsaville BJ, Kranzler HR, Ball S, Tennen H, Poling J, Triffleman E. Personality disorders in substance abusers: relation to substance use. J Nerv Ment Dis. 1998;186(2):87-95.

68. O'Brien CP, Woody GE, McLellan AT. Psychiatric disorders in opioid-dependent patients. J Clin Psychiatry. 1984;45(12 Pt 2):9-13.

69. Eibl JK, Gauthier G, Pellegrini D, Daiter J, Varenbut M, Hogenbirk JC, et al. The effectiveness of telemedicine-delivered opioid agonist therapy in a supervised clinical setting. Drug Alcohol Depend. 2017;176:133-8.

70. Eibl JK, Gomes T, Martins D, Camacho X, Juurlink DN, Mamdani MM, et al. Evaluating the Effectiveness of First-Time Methadone Maintenance Therapy Across Northern, Rural, and Urban Regions of Ontario, Canada. J Addict Med. 2015;9(6):440-6. 
71. Hser YI, Saxon AJ, Huang D, Hasson A, Thomas C, Hillhouse M, et al. Treatment retention among patients randomized to buprenorphine/naloxone compared to methadone in a multi-site trial. Addiction. 2014;109(1):79-87.

72. Gryczynski J, Mitchell SG, Jaffe JH, Kelly SM, Myers CP, O'Grady KE, et al. Retention in methadone and buprenorphine treatment among African Americans. J Subst Abuse Treat. 2013;45(3):287-92.

73. Agency of Health Protection and Promotion. Opioid Related Morbidity and Mortality Toronto Ontario [Available from: https://www.publichealthontario.ca/en/dataandanalytics/pages/opioid.aspx\#/drug].

74. Kurdyak P, Stukel TA, Goldbloom D, Kopp A, Zagorski BM, Mulsant BH. Universal coverage without universal access: a study of psychiatrist supply and practice patterns in Ontario. Open Med. 2014;8(3):e87-99.

75. Davis KA, Sudlow CL, Hotopf M. Can mental health diagnoses in administrative data be used for research? A systematic review of the accuracy of routinely collected diagnoses. BMC Psychiatry. 2016;16:263.

76. Meltzer EC, Averbuch T, Samet JH, Saitz R, Jabbar K, Lloyd-Travaglini C, et al. Discrepancy in diagnosis and treatment of post-traumatic stress disorder (PTSD): treatment for the wrong reason. J Behav Health Serv Res. 2012;39(2):190-201.

77. Nutt DS, M.; Zohar, J. Post Traumatic Stress Disorder: Diagnosis, Management and Treatment: CRC Press; 2009.

78. Weinstein D, Staffelbach D, Biaggio M. Attention-deficit hyperactivity disorder and posttraumatic stress disorder: differential diagnosis in childhood sexual abuse. Clin Psychol Rev. 2000;20(3):359-78.

79. Vickerman KA, Margolin G. Post-traumatic Stress in Children and Adolescents Exposed to Family Violence: II. Treatment. Prof Psychol Res Pr. 2007;38(6):620.

80. Naggara O, Raymond J, Guilbert F, Roy D, Weill A, Altman DG. Analysis by categorizing or dichotomizing continuous variables is inadvisable: an example from the natural history of unruptured aneurysms.

AJNR Am J Neuroradiol. 2011;32(3):437-40.

81. Locker TE, Baston S, Mason SM, Nicholl J. Defining frequent use of an urban emergency department. Emerg Med J. 2007;24(6):398-401.

82. Rask KJ, Williams MV, McNagny SE, Parker RM, Baker DW. Ambulatory health care use by patients in a public hospital emergency department. J Gen Intern Med. 1998;13(9):614-20.

\section{Declarations}

Ethics approval and consent to participate

This study was approved by the Research Ethics Board of Laurentian University in Sudbury, Ontario, Canada.

Consent for publication 
This study only used administrative health data, there was no primary data collection, therefore consent for publication from individual patients did not apply.

Availability of data and material

The datasets used during the current study are not publicly available due privacy reasons but aggregated data are included in this published article and its supplementary information files

Competing interests

Dr. David Marsh maintains the following roles: Chief Medical Director at CATC (Canadian Addiction Treatment Center), opioid agonist therapy provider. Dr. Marsh has no ownership stake in the CATC as a stipendiary employee. We do not foresee any conflict of interest as data will be made freely available to the public and neither the CATC, nor the Universities, have the ability to prevent publication and dissemination of knowledge. The authors have no conflicts declared. This does not alter our adherence the Harm Reduction Journal's policies on sharing data and materials

Funding

We thank our funders (Northern Ontario Academic Medical Association) through the Academic Funding Plan Innovation Fund for their support in completing this project, grant \# A-17-05.

Authors' contributions

KAM participated in the conceptualization, design, acquisition and analysis of data, writing, preparation and agreed to act as guarantor of the work of the article in question.

JKE participated in the conceptualization and design of this study. He also revised the article critically for important intellectual content and gave final approval of the version to be published. 
GG played a role in data set up, and analysis of this study, revised the article critically for important intellectual content and gave final approval of the version to be published.

BR played a leadership role in planning and conceptualization of this study. He also has contributed to the interpretation of the data, revised the article critically for important intellectual content and gave final approval of the version to be published.

$\mathrm{CM}$ played a leadership role in planning in planning and conceptualization of this study. He also has contributed to the interpretation of the data, revised the article critically for important intellectual content and gave final approval of the version to be published.

NEL played a leadership role planning and conceptualization of this study. She also has contributed to the interpretation of the data, revised the article critically for important intellectual content and gave final approval of the version to be published.

DCM has played a leadership role in overseeing the conceptualization, design, data collection and analysis of this study. He has also revised the article critically for important intellectual content and gave final approval of the version to be published.

All authors read and approved the final manuscript.

\section{Acknowledgements}

We thank IC/ES Data Analytic Services, more specifically Ryan $\mathrm{Ng}$ for his assistance with data extraction and database set up. We also thank members of the Patient and Family Advisory Committee for sharing their stories and helping to guide the research project. Lastly we would like to Matt Parotta and Lyne Morvan for editing the final draft of the paper.

\section{Tables}

Table 1: Patient Group Characteristics 


\begin{tabular}{|c|c|c|c|}
\hline Variable & Concurrent Mental and Opioid Use Disorder & Opioid Use Disorder Only & p-value \\
\hline & $\mathrm{N}=48,679(87.0)$ & $7,245(13.0)$ & 55924 \\
\hline \multicolumn{4}{|l|}{ Age } \\
\hline 15 to 24 & $8.727(17.9)$ & $1,514(20.9)$ & \multirow[t]{6}{*}{$<.0001$} \\
\hline 25 to 34 & $16,148(33.2)$ & 2,859 (39.5) & \\
\hline 35 to 44 & $10,712(22.0)$ & 1,383 (19.1) & \\
\hline 45 to 54 & $8,812(18.1)$ & 989 (13.7) & \\
\hline 55 to 64 & $3,348(6.9)$ & $338(4.7)$ & \\
\hline $65+$ & $932(1.9)$ & $162(2.2)$ & \\
\hline \multicolumn{4}{|l|}{ Sex } \\
\hline Male & $30,654(63.0)$ & $5,575(77.0)$ & \multirow[t]{2}{*}{$<.0001$} \\
\hline Female & $18,025(37.0)$ & $1,670(23.1)$ & \\
\hline \multicolumn{4}{|l|}{ Geography } \\
\hline Southern Urban & $37,887(87.9)$ & $5,209(12.0)$ & \multirow[t]{4}{*}{$<.0001$} \\
\hline Northern Rural & $2,240(79.0)$ & $593(21.0)$ & \\
\hline Northern Urban & $4,533(85.6)$ & $761(14.4)$ & \\
\hline Southern Rural & $4,016(85.5)$ & $682(14.5)$ & \\
\hline \multicolumn{4}{|l|}{ Income } \\
\hline 5 & $5,532(11.5)$ & $734(10.4)$ & \multirow[t]{5}{*}{0.0584} \\
\hline 4 & 7,014 (14.6) & 1,078 (15.2) & \\
\hline 3 & $8,690(18.1)$ & 1,282 (18.1) & \\
\hline 2 & $10,886(22.6)$ & $1,613(22.7)$ & \\
\hline 1 (lowest) & $16,020(33.3)$ & 2,388 (33.7) & \\
\hline HIV positive & $390(0.8)$ & $21(0.3)$ & $<.0001$ \\
\hline Deep tissue infection & $1,584(3.3)$ & $92(1.3)$ & $<.0001$ \\
\hline All-cause mortality (ACM) & $2,485(5.1)$ & $227(3.1)$ & $<.0001$ \\
\hline *One year continuous OAT & $8,757(37.6)$ & $903(35.7)$ & .0517 \\
\hline *Mean days buprenorphine (SD) & $55.0(167.8)$ & $34.8(121.8)$ & $<.0001$ \\
\hline *Mean days methadone (SD) & $356.8(441.0)$ & $344.6(409.8)$ & $<.0 .042$ \\
\hline
\end{tabular}

*ODB subgroup analysis $(n=28,500)$

Table 2: All-Cause Mortality, Acute Care Use and Treatment Retention in Patient Groups

\begin{tabular}{|c|c|c|c|c|c|c|}
\hline & Patients, N & Outcome, N (\%) & Unadjusted OR & Unadjusted 95\%CI & Adjusted OR & 95\% Wald \\
\hline \multicolumn{7}{|c|}{ Primary Outcome: All-cause mortality } \\
\hline \multirow{2}{*}{$\begin{array}{l}\text { MHdx } \\
\text { noMH (reference) }\end{array}$} & 48,679 & $2,485(5.1)$ & 1.7 & $1.5-1.9$ & 1.4 & \multirow[t]{2}{*}{$1.2-1.5$} \\
\hline & 7245 & $227(3.1)$ & & & & \\
\hline \multicolumn{7}{|c|}{ Secondary Outcome: ED visits } \\
\hline MHdx & 48679 & $24,643(59.9)$ & 3.6 & $3.4-3.7$ & 3.9 & \multirow[t]{2}{*}{$3.7-4.1$} \\
\hline noMH (reference) & 7245 & $2142(29.6)$ & & & & \\
\hline \multicolumn{7}{|c|}{ Secondary Outcome: Hospitalizations } \\
\hline MHdx & 48,679 & $38,034(78.1)$ & 2.8 & $2.7-3.0$ & 2.6 & \multirow[t]{2}{*}{$2.5-2.7$} \\
\hline noMH (reference) & 7245 & $4,041(55.8)$ & & & & \\
\hline \multicolumn{7}{|c|}{ *Secondary Outcome: One-year treatment retention } \\
\hline MHdx & 23,268 & $8,758(37.6)$ & 1.1 & $0.9-1.2$ & 1.0 & \multirow[t]{2}{*}{$0.9-1.1$} \\
\hline noMH (reference) & 2,532 & 903 (35.7) & & & & \\
\hline
\end{tabular}




\section{Figures}

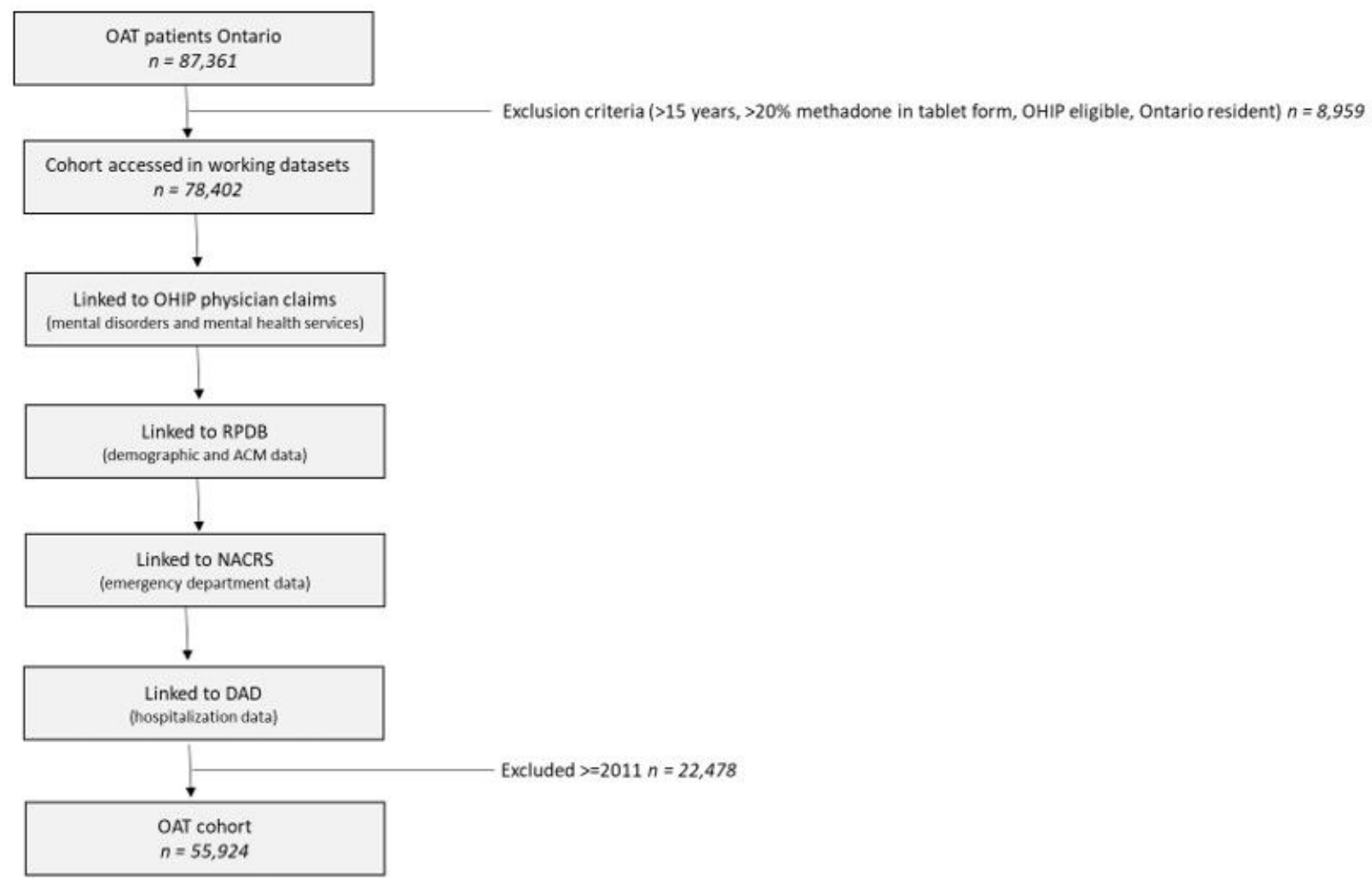

Figure 1

Flow Chart Outlining Data Build Including Linkages. 


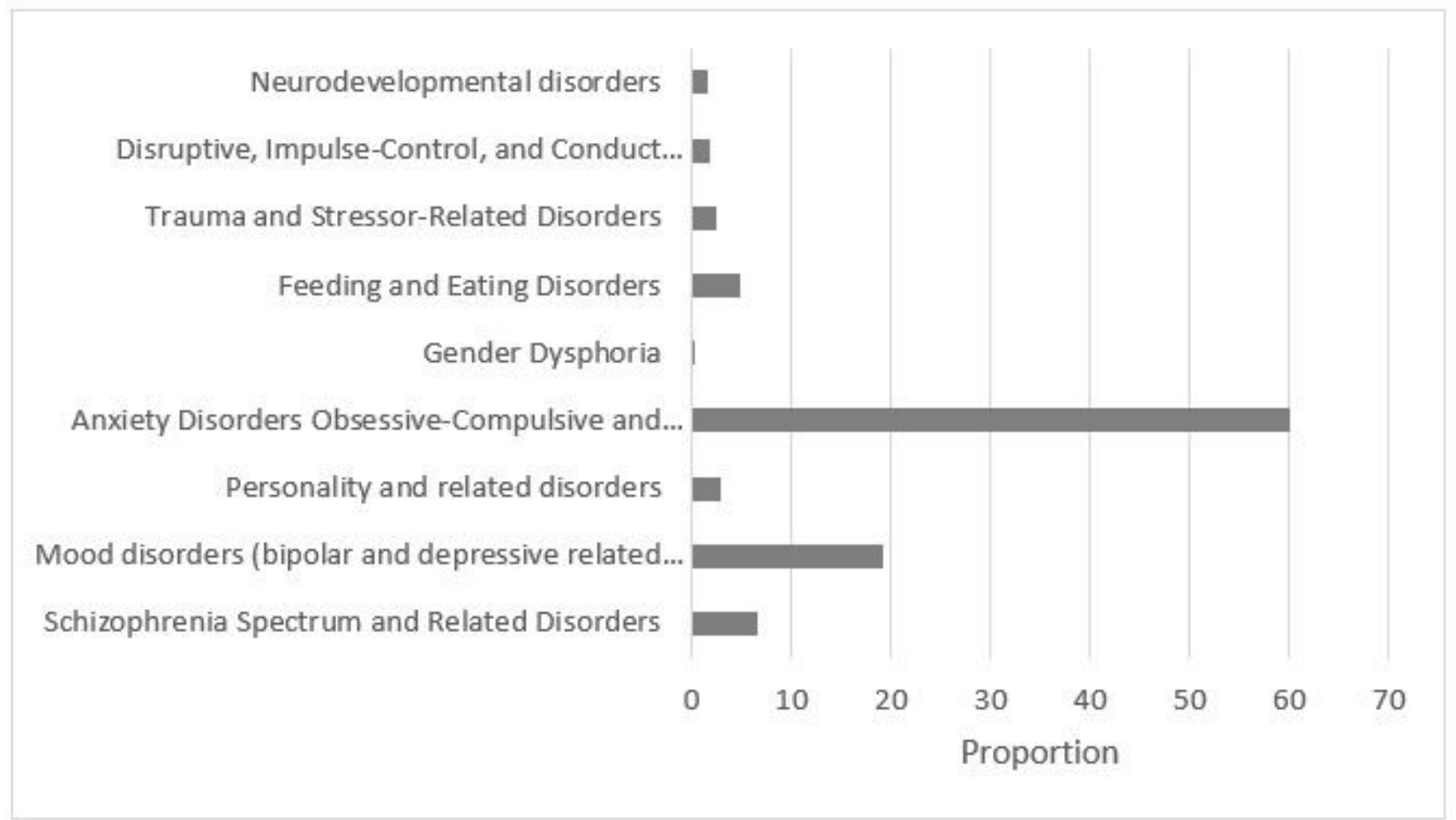

\section{Figure 2}

Proportion of Diagnoses of Mental Disorders for Patients Enrolled in OAT

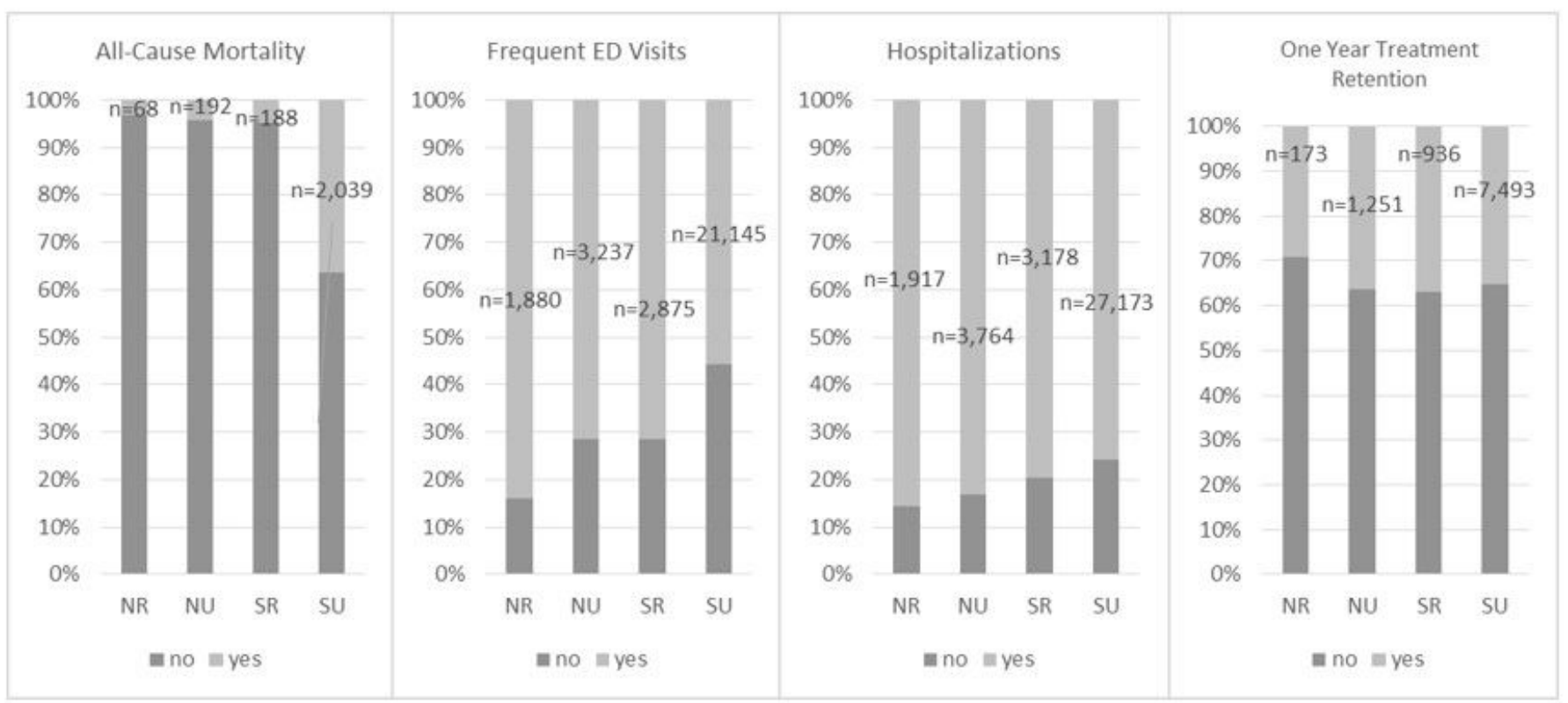

Figure 3 
Proportion of Patients for Outcomes by Place of Residence

\section{Supplementary Files}

This is a list of supplementary files associated with this preprint. Click to download.

- AppendixA.docx

- AppendixE.docx

- AppendixB.docx

- AppendixD.docx

- AppendixC.docx 